Contents List available at RAZI Publishing

Journal CleanWAS

Journal Homepage: http://www.razipublishing.com/journals/journal-cleanwas/

https://doi.org/10.26480/jcleanwas.01.2017.01.05

\title{
PROBLEMS AND CURRENT PRACTICES OF SOLID WASTE MANAGEMENT IN THE CITY OF AL-MARJ, LIBYA
}

Jaouda R. Jaouda Hamad1, Marlia M. Hanafiah1,*, Shardy Abdullah2

1School of Environmental and Natural Resource Sciences, Faculty of Science and Technology, Universiti Kebangsaan Malaysia, 43600 UKM Bangi, Selangor, Malaysia.

2Faculty of Architecture and Ekistics, Universiti Malaysia Kelantan, Pengkalan Chepa, 16100 Kota Bharu, Kelantan, Malaysia

${ }^{*}$ Corresponding author. Tel.: +60389215865; Fax.: +60389253357

E-mail address: mhmarlia@ukm.edu.my

This is an open access article distributed under the Creative Commons Attribution License, which permits unrestricted use, distribution, and reproduction in any medium, provided the original work is properly cited

\section{ARTICLE DETAILS}

Article history:

Received 27 September 2016

Accepted 13 December 2016

Available online 10 January 2017

Keywords:

Solid waste; sustainable management; environmental awareness; 3R's concept; Libya \begin{abstract}
Solid waste management is one of the most difficult environmental problems in the urban center of developing countries, where services are often grossly deficient, particularly in low-income settlements. These settlements often comprise a sizable proportion of the city's area and population. Rapid urban growth, increasing population density, traffic congestion, air and water pollution, increasing per capita generation of solid waste, and lack of land for waste disposal contribute to the aggravation of solid waste management problems. Future demands will increase with expanding residential, commercial, and industrial sectors and increasing economic development. This paper aimed to examine the current practice of solid waste management programs in the city of Al-Marj, which is located in the central northeastern area of Libya. Various problems of wastes in past and present, waste minimization hierarchy and people attitudes and awareness towards' waste management are defined. We found that the lack of effective relationship between various stakeholders contributes to the unsuccessful good solid waste management practices in the study area. Sustainable solid waste management in Libya can be achieved through active participation of these stakeholders.
\end{abstract}

\section{INTRODUCTION}

Municipal solid waste management has appeared as one of the greatest issues facing by many developing countries [17]. Problems in solid waste management of most developing countries, such as Libya, differ from those found in industrialized countries in terms of composition, density, political and economic framework, amount of waste, access to waste collection, awareness and attitude. The wastes are heavier, wetter and more corrosive in developing cities as compared to the developed cities [9]. Over the past 50 years, the practice of waste management has emerged and currently it encompasses disposal, treatment, reduction, recycling, segregation and modification [12]. Despite increasing industrialization and urbanization, dumping of solid waste, particularly in landfills, remains a major means of disposal and implied treatment [16]. Major developments have occurred in landfill technology and in the legislative control of waste categories that can be subject to disposal by landfilling. Unfortunately, many landfills remain primitive in their operations. Alternative treatment technologies for solid waste management are available, namely, incineration with heat recovery and waste gas cleaning as well as accelerated composting [4]. However, these technologies are criticized by environmentalists because of possible hazardous emissions, failure to eliminate pathogenic agents, and failure to immobilize heavy metals. Landfill operators and contractors are also criticizing these technologies on the basis of waste management economics [12].

Different definition has been given to refer to the solid waste. Rimberg [24] defined solid waste as garbage, refuse and other discarded solid materials, including solid waste materials resulting from industrial, commercial and agricultural operations, and from community activities, but does not include solids or dissolved materials in domestic sewage or other significant pollutants in water resources, such as silt, dissolved or suspended solids in industrial wastewater effluents, dissolved materials in irrigation return flows or other common water pollutants. Jones and Hollier [13] defined solid waste as a reflection of human appraisal. Solid wastes can be defined as all wastes in solid form which are discarded as useless or unwanted and in general arise from human activities [19]. Qusus [21] defined it as any unwanted material that is not discharged to the atmosphere or via pipe, and cannot flow directly into streams or rise immediately into the air while others defined solid wastes can be as unwanted, or any discarded materials arising from human's activities and which are not free-flowing.

1.1 Waste Minimization Hierarchy

To prioritising waste management practices, the waste management hierarchy that is a nationally and internationally accepted guide has been used to obtain optimal environmental outcomes. It sets out the preferred order of waste management practices, from most to least preferred [30]. Environmental Protection Agency (EPA) has ranked the most environmentally sound strategies for municipal solid waste. Source reduction (including reuse) is the most preferred method, followed by recycling and composting, energy recovery, and, lastly, treatment and disposal.

This hierarchy is used as a main framework to develop waste management policies. Waste hierarchy which has been developed in the $1970 \mathrm{~s}[7,14,21]$ was placed in the following order: Waste minimization, prevention, reduction, reusing, recycling, composting, incineration and disposal. Barr [3] defined waste hierarchy order as a waste management behavior which relates to recycling, reusing and reduction (Figure 1).

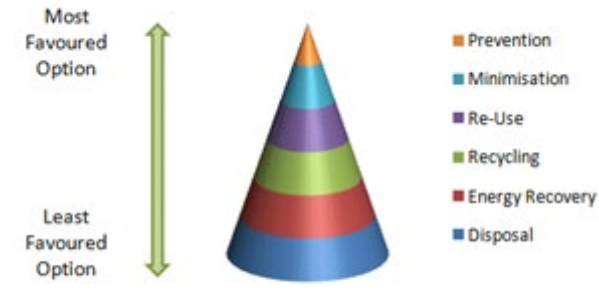

Fig. 1: Shows Waste Management Hierarchy [3]

\section{$2.0 \quad$ METHODOLOGY}

\subsection{Study Area}

This study was carried out at Al-Marj city, which is located in the northeastern Libya (Figure 2) and lies on the coast of the Mediterranean Sea. Al-Marj is situated on the Cyrenaica plateau at the western edge of Jebel Akhdar and has an estimated population of 85,315 people as of 2012 . In the last few decades, solid waste has been the most prominent among the multitude of problems in the rapidly urbanizing city of Al-Marj. In Libya, solid wastes are generated from domestic, commercial and industrial activities and are scattered at a large scale on any unused parcel of land, around buildings, and in open market places. 


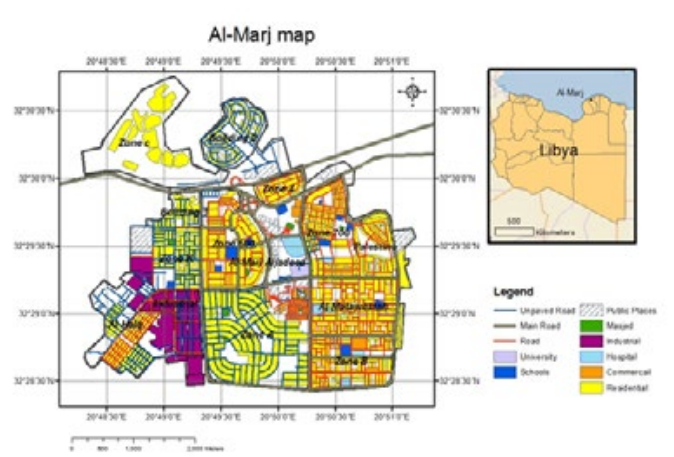

Fig. 2: Maps shows the Four Regions of Al-Marj City

2.2

Conceptual Framework

The conceptual framework for sustainable solid waste management in Al-Marj city, Libya is illustrated in the Figure 3. The institutional, cultural, technical, economic and social constraints serve as the independent variables, while residential solid waste management in Al-Marj City is the dependent variable.

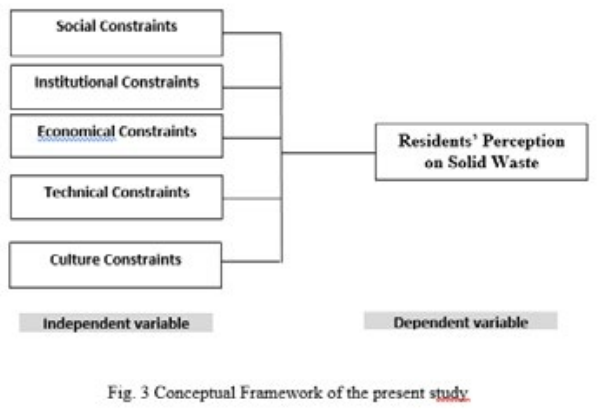

2.3

Research Design

\subsubsection{Pilot Study (Pre-test)}

The aim of the pilot study was to test the experimental procedure and the validity of the questionnaire before embarking on the main study, to improve reliability of the results, and to check errors and level of difficulty of the questions listed in the questionnaire. Three steps were carried out during the pilot study. First, the questionnaire was checked for their conformity to the research questions and objectives. Second, the original English version was translated into Arabic language for respondents to easily understand. Third, 21 samples of residents in the city were randomly selected to participate in the pilot study. The respondents who participated in the pilot study were not included in the actual research. Internal consistency reliability of the results of the pilot study was determined using Cronbanch's Alpha. The value of the reliability coefficient obtained was $\alpha=0.77$. The results indicate that the questionnaires for this research were reliable and can be used for the study. The value of the reliability coefficient obtained divided the study area into four administrative units that vary in terms of area and proportion of the population. The questionnaires were then distributed randomly to the respondents.

\subsubsection{Background of the Respondents}

Table 1 provides the characteristics of the respondent based on their demographic background. Almost all of the respondents were Libyan $(92.3 \%)$ compared to other ethnics $(7.7 \%)$. They were from various groups of age, under 20 years old (14.1\%), 21 to 29 years old (38\%), 30 to 39 years old (34.2\%), 40 to 49 years old $(10.2 \%), 50$ to 59 years old $(2.9 \%)$ and more than 60 years old $(0.6 \%) .54 .8 \%$ of the respondents were male and 45.2 $\%$ were female. Majority of the respondents completed the university level (72.4\%). Government servants constitute $35.1 \%$ of the total respondents, private employees $(4.8 \%)$ and running their own business $(7.1 \%)$. The others were unemployed, housewife and students. As most of them were unemployed, $46.7 \%$ did not generate any income. Only $26.3 \%$ of them earned more than LYD600 per month. More than half of the respondents stay in apartment (63.7\%), $24.3 \%$ in flat and $10 \%$ in semi-detached houses.

\begin{tabular}{|c|c|c|}
\hline & rempunas & 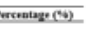 \\
\hline 2 What & 40 & 9223 \\
\hline & & \\
\hline 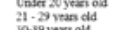 & $\begin{array}{l}68 \\
183 \\
183\end{array}$ & $\begin{array}{l}141 \\
38 \\
38\end{array}$ \\
\hline 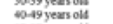 & 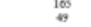 & $\begin{array}{l}3.2 \\
10.2\end{array}$ \\
\hline $\begin{array}{l}\text { sasy yeass oul } \\
\text { cy yers int atore }\end{array}$ & $\begin{array}{l}14 \\
3\end{array}$ & $\begin{array}{l}29 \\
00\end{array}$ \\
\hline
\end{tabular}

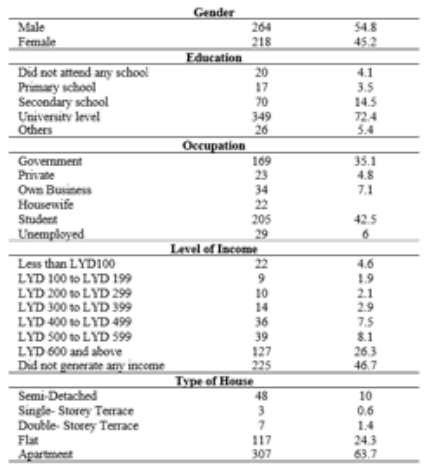

2.3.3 Primary Data Collection

Primary data are defined as information directly collected by a researcher using techniques such as surveys, interviews, focus group discussions, or observation. Primary data in the present study that were obtained through surveys using constructed questionnaire were then processed, analysed and evaluated. This research focused on examining the constraints of residential solid waste management and the recycling activities in the city of Al-Marj. A total of 700 questionnaires with cover letter were sent out to the residents of Al-Marj city, who were approached randomly using a convenient random sampling method. The background information about the purpose of the research and the schedule of submission of the questionnaires were provided to the respondents. These steps were performed in compliance to the advice to produce a brief, yet comprehensive cover letter to introduce the purpose of the study during data collection.

The data were collected through a questionnaire that used frequency and style responses to obtain information pertaining to sustainable solid waste management in Al-Marj city, Libya. The research instruments were fully tested by distributing the questionnaire to 700 randomly selected residents. Out of 700 questionnaires sent out to the residents, only 482 questionnaires were returned and analyzed, yielding a response rate of $69 \%$ (Table 2). A total of 357 respondents were chosen based on the sampling table in identifying the sample size. The current study employed simple random sampling techniques to avoid bias and to ensure that each resident has an equal chance of being selected. Amin [1] explained that randomization is effective in creating equivalent representative groups that are essentially the same on all relevant variables assumed by the researcher. Purposive sampling was used in selecting the respondents to study only the performance of the residents.

The questionnaires for each area were equally distributed among the income group (i.e., high, middle and low income groups). The questionnaires were first written in English and then translated to Arabic. The reasons for writing the questionnaire in Arabic include the fact that majority of the city residents do not understand English and to avoid any biased views on the returned questionnaires. These questionnaires were randomly distributed in four regions of Al-Marj City (East, West, South and North) as shown in the Figure 2. Data collections were done from January 2012 to November 2012. The response rate based on each targeted area in Al-Marj City was calculated. These questionnaires were personally distributed to the respondents in their homes. The respondents were provided prepaid envelopes and were required to return them by mail within the time frame given (four months). Follow-ups were conducted for those who did not return their completed questionnaires in time. The returned questionnaires were then analyzed.

Table 2- Response Rates for Each of the Four Regions in Al-Marj City

\begin{tabular}{cccc}
\hline Region & Questionnaires sent & $\begin{array}{c}\text { Questionnaires } \\
\text { returned }\end{array}$ & $\begin{array}{c}\text { Response rate for each area } \\
(\%)\end{array}$ \\
\hline West Al-Marj & 250 & 214 & 835 \\
East Al-Marj & 150 & 81 & 68 \\
North Al-Marj & 150 & 84 & 51 \\
South Al-Marj & 150 & 103 & 62 \\
Total & 700 & 482 & 80.3 \\
\hline
\end{tabular}

\subsubsection{Secondary Data Collection}

Secondary data are the data that have already been collected and are readily available from other sources. Secondary data may also be available when primary data cannot be obtained at all. The advantages of secondary data include its being economical, involves less time and effort and 
affordability. Secondary data also allow primary data collection to be more specific because gaps and deficiencies will be understood and additional information to be collected will be identified. Furthermore, secondary data help to improve understanding on the problem, as well as provide a basis for comparison of the data collected by the researcher. Secondary data were collected from different sources such as articles, newspapers, magazines, conference proceedings (local and international), reports, and journals, and from accessible web sites. The obtained data were then used to design the research instruments to justify the findings and to correlate the results.

All information gathered formed the basis for the evaluation in the current study. Secondary data were also utilized to determine the current practice of solid waste disposal and collection in Al-Marj City, factors behind the ongoing problem of solid waste management by responsible parties, method of disposal, role of the private sectors in Al-Marj City, the incineration process, and reasons for participation and non-participation of residents in Al-Marj City in the solid waste management. Furthermore, the secondary data looks into plans that may be implemented by MSWM in the coming years, based on two Libya Master Plans, and how solid waste disposal can be made sustainable.

\subsubsection{Data Processing and Analysis}

The data collected was processed by using Statistical Package for Social Science (SPSS) program for Windows (Version 20.0). Descriptive statistics were used to organize and describe the characteristics of the collection of data. Descriptive statistics, such as the mean score, standard deviation, frequencies, cross tabulations, and measures of central tendency of the data, were included in this study. Descriptive analysis was used to present the raw data into a form that makes it easier to be understood and interpreted [25].

How well the predicted values from a forecast model "fit" with the real-life data has been obtained from the correlation coefficient analysis. According to Pallant [18], correlation analysis needs to be conducted to examine the strength and direction of a linear relationship between two variables. The value of the coefficient ranges from negative $(-1)$ to positive $(+1)$ and 0 coefficient indicates no correlation at all between the variables. According to Cohen et al (2000), correlation of 0.14 to 0.29 (+ or-) indicates a week relationship, 0.3 to 0.49 (+or-) is fair and 0.5 to 1.0 (+or-) indicates a strong positive or negative relationship. In the present study, one-way analysis of variance (one-way ANOVA) was conducted to compare means of two or more samples (using the $\mathrm{F}$ distribution).

The term "chi-square" refers both to a statistical distribution and to a hypothesis testing procedure that produces a statistic that is approximately distributed as the chi-square distribution. In this study, the Chi Square test used to measure whether there is a significant difference between the effects of two categorical independent variables on a categorical dependent variable. A t test for independent means was used for hypothesis testing with scores from two entirely separate groups of people. The assumptions of the $t$ test for independent means are that the two populations are normally distributed and have the same variance. However, the t-test gives fairly accurate results when the true situation is moderately different from the assumptions [2].

Reliability analysis allows to determining the extent to which a scale produces consistent results if the measurements are repeated. The factor extracted from the factor analysis involves multiple-item scale; Cronbach's coefficient alpha was used to determine the reliability of the various items used in the study. It ensures that scales adopted in this study were not ambiguous and that all items within a factor were measuring the same underlying dimension. A high value of the alpha coefficient is an indication of greater consistency among the items for each factor and the confidence that the measurements are reliable. This study followed the minimum reliability acceptance level, where a 0.7 is considered acceptable. However, all the Cronbach's coefficient alpha values obtained in this study are above the 0.7 minimum acceptable values.

\section{0}

\section{RESULTS AND DISCUSSION}

3.1 Recycling

With regard to the awareness of residents on recycling of solid wastes in the city of Al-Marj, 96.9\% of the respondents were not aware of recycling solid waste (see Figure 4). Learning that most of the residents did not know any aspect about this program is disappointing. One reason for such ignorance is the lack of knowledge and information, which is due to the absence of media, communication, activities, or recycling campaigns. Read [23] proved that communication with the public on waste matters impacts individual commitment to recycling, as well as helps in managing recyclables as this also shows the commitment of the local authority to recycling.

In the present study, list of sources that may make the residents aware of such recycling program were included. The results show that only $3.3 \%$ of the participants learned about recycling through television, $0.4 \%$ from reading national newspaper, and only $0.2 \%$ obtained information from local newspapers and the radio. The success of a program on solid wastes management requires public participation. It is stated that individual participation is the common factor among recycling programs, whereas their procedural or organizational structures vary.

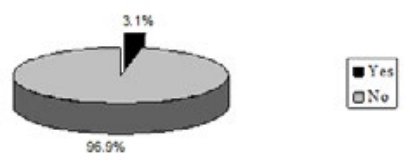

Fig. 4 Participant Awareness on Recycling of Solid Wastes in Al-Marj City

\subsection{Environmental condition in Al-Marj City}

The respondents were asked to evaluate the environmental condition in the city in which they live. Accordingly, many of them considered their environment is polluted (73.7\%). Only $16.3 \%$ stated that their area was one of the cleanest in the neighborhood (Figure 5). Tinmaz and Demir [27], generated similar observations in their research done in Turkey. They stated that in a number of places in their country, the environmental condition has been considered as polluted. Toula [28] stated that although most urban inhabitants in poor countries protest the poor environmental conditions in their settlements, they are often not ready to organize groups to present their concerns to respective authorities. Gebril et al. [11] observed the same problem in the city of Benghazi, in the East part of Libya where they did state the environment conditions is very worse.

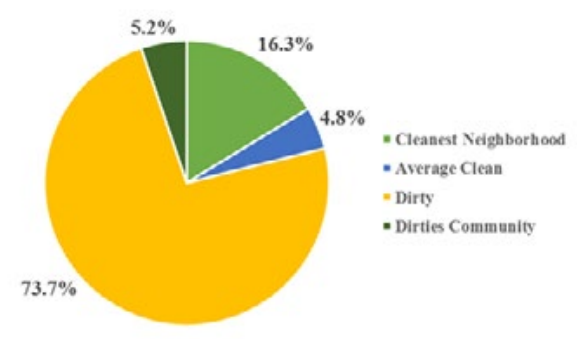

Fig. 5 Ranking of environmental condition in Al-Marj City

\subsection{Knowledge of Residents on How to Recycle Solid Wastes}

$89 \%$ of the respondents stated that they have no such knowledge on how to recycle solid wastes, and $7.3 \%$ stated that they only know a small amount (Table 3). In a study of recycling roles within the household, Meneses and Palacio [16] recommended that educational programs include components to build ecological conscience or environmental knowledge, ecological involvement, and ecological self-realization among citizens. Another research indicated a need for environmental education in Libya [11], which is highly necessary in Al-Marj City. Espeut [10] stated that $61.1 \%$ of the respondents in their study believe that they have enough information on the ways to protect the environment. However, based on the survey responses, the author concluded that Jamaicans need greater environmental information. Espeut [10] recommended that the first task of environmental education should be to convince the public that they need environmental information. 
Table 3: Knowledge of Respondents on How to Practice Solid Wastes Recycling

\begin{tabular}{lc}
\hline \multicolumn{1}{c}{ Items } & Frequency (\%) \\
\hline Know nothing & $429(89 \%)$ \\
Know a little bit & $35(7.3 \%)$ \\
Neutral & - \\
Know something & $17(3.5 \%)$ \\
Know a lot & $1(0.2 \%)$ \\
\hline
\end{tabular}

3.4 Level of Agreement on the Importance of Solid Wastes Recycling The respondents were asked regarding their position on recycling the wastes in their house. The results indicate that most residents (91.5\%) consider recycling as a very important activity. This finding is similar to previous studies by Perrin and Barton [20] and Davis et al. [7] that identified environmental concerns as the main reason for participation in recycling The residents are likewise concerned with the availability of landfills. This is consistent with previous studies $[12,22,29]$ stating that recycling can be an option for social or environmental reasons as it extends the life of the landfill.

However, less than $1 \%$ of the respondents in the city believe that recycling is not important. The main reasons for their disagreement are inconvenience and lack of facilities. In a survey conducted in Sheffield, Coggins [5] similarly noted that $35 \%$ of non-recyclers cited inconvenience and lack of facilities as the main barriers to their participation; 'nothing to recycle' is a less common reason for not recycling. The level of participation in a scheme is clearly critical for success. However, the success of recycling does not only involves the number of participants, but also how well people participate [26]. Although only a small number of respondents indicated that recycling of solid wastes is not important, particular attention should be taken to enlighten them on the value of recycling.

Table 4: Knowledge of Respondents on the Materials Sent for Recycling

\begin{tabular}{lc}
\hline \multicolumn{1}{c}{ Items } & Frequency (\%) \\
\hline Do not know & - \\
Not at all important & $1(0.2 \%)$ \\
Not very important & - \\
Fairly important & $40(8.3 \%)$ \\
Very important & $441(91.5 \%)$ \\
\hline
\end{tabular}

3.5

Attitude of Residents towards Solid Wastes Recycling in Al-Marj

City

Attitude towards solid waste recycling was determined by providing the respondents with four choices in the questionnaires (see Table 5). The findings from the data analysis show that many residents do not recycle or are not involved in recycling, and $3.1 \%$ of the respondents indicated that they were not aware of such activities. It is reported that recycling is one of the cardinal strategies in managing solid waste in many developing countries, such as India, Brazil, Mexico, Columbia, the Philippines and Nigeria. However, in this city of Al-Marj, the attitude towards solid waste recycling is clearly negative.

Table 5: Attitude of Respondents towards Solid Wastes Recycling

\begin{tabular}{lcc}
\hline \multicolumn{1}{c}{ Items } & Frequency & Percentages \\
\hline I do not recycle & 451 & $93.6 \%$ \\
I recycle if it does not require additional effort & 7 & $1.5 \%$ \\
I recycle even if it requires additional effort & 9 & $1.9 \%$ \\
Do not know & 15 & $3.1 \%$ \\
\hline
\end{tabular}

Landfilling is proposed by various studies, private companies and state agencies as the best solution for MSW management in Greece. Some studies even support that landfill construction has a positive impact, since it enforces environmental consciousness in people. Furthermore, recycling activities have generally a positive social picture where social desire for participation in recycling and social opposition to landfill construction are both significant aspects to be considered [8].

4.0

\section{CONCLUSIONS}

The results of the present study show that the authorities in charge of solid waste management in the city is lack of experience and effective practices in the process of collection, transportation and disposal of waste. Local authorities are still utilizing the traditional methods of collection and transport of waste. Waste is randomly disposed in an unsanitary open dumping area where no health standards are enforced. Authorities dispose waste without prior analysis of population increase and urbanization in the outskirts of the city and the waste collection process in the entire city is not well implemented. In addition, solid waste management in the city is improper and poor, while vehicles are not in good condition and require maintenance.

Solid waste collection should be performed at the appropriate time based on location and living situation; for example, solid waste from shops must be collected after shops close. Solid waste should not be burnt in garbage containers, in places allocated for waste collection, or even in the dump site because burning would cause air pollution and respiratory diseases to people living near these places. In addition, current dumpsite must be closed and new sanitary landfill sites have to be designed and constructed because the current dumpsite causes environmental pollution to Al-Marj and its surrounding areas. The replacement of the new sanitary landfill must be constructed not more than $5 \mathrm{~km}$ away from the city. Moreover, the landfill must adhere to health requirements for the control of air and water pollution and it also has to be in accordance with policies established to preserve the global environment.

5.0 ACKNOWLEDGMENT

Marlia Mohd Hanafiah was financed by the UKM research grants (FRGS/2/2013/STWN01/UKM/03/1) and (TD-2014-012).

\subsection{REFERENCES}

[1] Amin, M.E. (2005). Social Science research: conception, methodology and analysis. Kampala: Makerere University Press.

[2] Aron, A., Aron, N.E., \& Elliot, J.G. (2006). Statistics for Psychology, 4th edition, by Pearson Education, Inc.

[3] Barr, S. (2007). Factors Influencing Environmental Attitudes and Behaviors: A UK case Study of Household Waste Management. Environment and Behavior, 39(4), 435.

[4] Cheremisinoff, P. N., \& Ferrante, L. M. (2013). Waste reduction for pollution prevention. Butterworth-Heinemann.

[5] Coggins, C. (1994). Who is the recycler? Journal of Waste Management, 2, 69-75.

[6] Corder, G.W., \& Foreman, D.I. (2009). Nonparametric Statistics for NonStatisticians: A Step-by-Step Approach Wiley.

[7] Davis, G., Phillips, P.S., Read, A.D., \& Iida, Y. (2006). Demonstrating the Need for the Development of Internal Research Capacity: Understanding recycling participation using the Theory of Planned Behaviour in West Oxfordshire, UK. Resources, Conservation and Recycling, 46 (2):115-127.

[8] Dimitriou, A., Hatzinikita V. and Christidou V. (2005), Solid waste management: Greek citizens' knowledge and attitudes. Proc. 9th Int. Conf. on Environmental Science and Technology, University of the Aegean, pp. 289-298.

[9] Egun, N. Kingsley (2012). The Waste to Wealth Concept: Waste Market Operation in Delta State, Nigeria. Greener Journal of Social Sciences. 2 (6), 206-212.

[10] Espeut, P. (1999). Attitudes to the Environment in Jamaica, 1998. Prepared by the Caribbean Coastal Area Management Foundation.

[11] Gebril, A. (2011), Factors Affcting Public Participation in the recycling of municipal solid waste in Libya: Acase study of Banghazi city, PhD Unpublished Thesis, Universiti Sains Malaysia, sPulau Pinang, Malaysia.

[12] Hamer, G. (2003). Solid waste treatment and disposal: effects on public health and environmental safety. Biotechnology Advances, 22(1), 71-79.

[13] Jones, G., and Hollier, G. (1977). Resources, Society and Environmental Management. London, Paul Chapman Publishing Ltd.

[14] Kirkpatrick, N. (1993). Selecting a Waste Management Option Using a Life-cycle Analysis Approach. Packaging Technology and Science, 6: 159159.

[15] Medina, M. (2010). Solid wastes, poverty and the environment in developing country cities. World Institute for Development Economic Research (UNUWIDER) Working Papers. Chicago.

[16] Meneses, G., \& Palacio,A. (2005). Recycling Behavior: A multidimensional Approach. Environment and Behavior, 37: 837-860.

[17] Ogwueleka, T. Ch (2009). Municipal Solid Waste Characteristics and Management in Nigeria. Iran. J. Environ. Health. Sci. Eng., 6 (3), 173-180.

[18] Pallant, J. (2007). SPSS Survival Manual, McGraw Hill.

[19] Peavy, H.S., Rowe, D.R., \& Tchobanoglous, G. (1985). Environmental Engineering. McGraw-Hill, Inc., New York.

[20] Perrin, D., \& Barton, J. (2001). Issues associated with transforming households attitudes and opinions into materials recovery: A review of two kerbside recycling schemes. Resources, Conservation and Recycling, 33 (1): 61-74.

[21] Qusus S. K. (1988). Composition and Generation rate of the solid waste of hospitals and medical laboratories in Amman. MSc. Thesis, Faculty of Graduate studies, Jordan University, Amman, Jordan. 
[22] Rasmussen, C., Vigso, D., Ackerman, F., Porter, R., Pearce, D., Dijkgraaf, E., \& Sarifah Y. (2009). Solid Waste Management Hierarchy-application towards The concept of Green Technology. Green technology on waste management: current knowledge and practices. Presented at Green Technology on waste management: current knowledge and practices,Kaula Lumpur.

[23] Read, A.D. (1998). Getting the message across: recycling in Kensington and Chelsea. Journal of Education and Information, 17, 299-314.

[24] Rimberg, D., (1975). Municipal solid waste management: Noyes Data Corporation.

[25] Salkind, N. J. (2009). Statistics for people who (think they) hate statistics: EXCEL 2007 Edition: Sage Publications, Inc.

[26] Thomas, C. (2001). Public Understanding and its Effect on Recycling Performance in Hampshire and Milton Keynes. Recourses, Conservation and Recycling, 32, 259-274.

[27] Tinmaz, E., \& Demir, I. (2006). Research on Solid Waste Management System: to improve Existing Situation in Corlu Town of Turkey. Waste Management, 26(3), 307-314.

[28] Toula, F. (2005). Urban Challenges in Senegal. Dakar, Ozu Press.

[29] Wang, F.S., Richardson, A.J., \& Roddick, F.A., (1997). Relationships between Set-out Rate, Participation Rate and Set-out Quantify in Recycling Programs. Resource, Conservation Recycling, 20, 1-17.

[30] ZeroWaste (2012). Waste Management Hierarchy. [Online]. [Accessed 11th December 2012]. Available from World Wide Web: http://www. zerowaste.sa.gov.au/About-Us/waste-management-hierarchy. 